\title{
FATAL PULMONARY THROMBOEMBOLISM IN GASTRECTOMY INTRAOPERATIVE PROCEDURES BY GASTRIC ADENOCARCINOMA CASE REPORT
}

\author{
Cláudio Bresciani, Pedro C. M. Borges, Joaquim J. Gama-Rodrigues, \\ Roberto Yamashita, Carlos F. S. Marques, Victor Strassmann and \\ Henrique Walter Pinotti
}

RHCFAP/2974

BRESCIANI, C. et al. - Fatal pulmonary thromboembolism in gastrectomy intraoperative procedures by gastric adenocarcinoma. Rev. Hosp. Clín. Fac. Med. S. Paulo 54 (4): 115 - 120, 1999.

SUMMARY: The case of a patient with gastric adenocarcinoma with indication for gastrectomy is reported.

The surgery took place without complications. A palliative, subtotal gastrectomy was performed after para-aortic lymph nodes compromised by neoplasm were found, which was confirmed by pathological exam of frozen sections carried out during the intervention. At the end of the gastroenteroanastomosis procedure, the patient began to show intense bradycardia: 38 beats per minute (bpm), arterial hypotension, changes in the electrocardiogram's waveform (upper unlevelling of segment ST), and cardiac arrest. Resuscitation maneuvers were performed with temporary success. Subsequently, the patient had another circulatory breakdown and again was recovered. Finally, the third cardiac arrest proved to be irreversible, and the intra-operative death occurred.

Necropsy showed massive pulmonary embolism. The medical literature has recommended heparinization of patients, in an attempt to avoid pulmonary thromboembolism following major surgical interventions. However, in the present case, heparinization would have been insufficient to prevent death. This case indicates that it is necessary to develop preoperative propedeutics for diagnosing the presence of venous thrombi with potential to migrate, causing pulmonary thromboembolism (PTE). If such thrombi could be detected, preventative measures, such as filter installation in the Cava vein could be undertaken.

DESCRIPTORS: Thromboembolism. Prophylaxis. Anticoagulation. Gastric adenocarcinoma. Gastrectomy.

The occurrence of thromboembolic phenomena in the perioperative period has concerned the medical establishment, especially surgeons, during the past few years. The finding of massive pulmonary embolism in necropsies occurs at a very high rate. In the United States, pulmonary thromboembolism (PTE) is found in $28 \%$ of necropsies, IS fatal for 0.5 to 1 in every one thousand inhabitants per annum, and responds for 300,000 to 600,000 hospitalizations per year 1,2 .

As early as 1856, Rudolf Virchow defined vascular thrombosis and its triad-alteration of vessels, alteration of blood elements, and alteration of blood flow - and their relation with pulmonary embolism. From his studies, the bases for the thrombosis treatment were established. In 1894, Von Strauch was the first to describe thrombosis following surgery ${ }^{3}$.

The prophylactic principles were initially proposed in 1945 by DahlInversen (4), basically involving precocious mobilization. However, the use of prophylaxis was not widely used until the 1970's, when different prophylactic methods were devel-

From From Clinical Surgery Division of the University of São Paulo Medical School, SãoPaulo-Brazil. oped and many randomized trials proving the efficacy of PTE prophylaxis were performed ${ }^{5}$.

\section{CLINICAL CASE}

The patient was 74 years old, male, white, and was admitted into the hospital complaining about burning epigastric pain for the previous 8 months that improved with the use of antacids. He mentioned progressive postprandial cramming of the stomach in the period, accompanied by nausea. In the week preceding his admission, he had had postprandial vomiting. 
He was a cigarette addict, having consumed five cigarettes a day for 40 years. He had lost $8 \mathrm{~kg}$ and his usual weight was $74 \mathrm{~kg}$. As a surgical antecedent, he mentioned having undergone an appendectomy 48 years ago.

At the physical exam, he was in general good condition, ruddy, hydrated, thin, with a body mass index (BMI) of $21.4 \mathrm{~kg} / \mathrm{m}^{2}$, without cervical or inguinal adenomegaly. His weight was $65.8 \mathrm{~kg}$, with a $130-\mathrm{mmHg}$ systolic blood pressure and $80 \mathrm{mmHg}$ diastolic, a respiratory rate of 18 inhalations per minute, 88 beats per minute (bpm) peripheral pulse, and $36.2{ }^{\circ} \mathrm{C}$ axillar temperature.

A thorax exam revealed lungs with normal-expansiveness, the presence of a bilateral vesicular murmur, and the absence of adventitious noises; the heart showed normal ictus and steady auscultation. The abdomen was level, slightly hollowed, there was a MacBurney scar in the right iliac region, palpation was painless, and there was no perception of a mass; the liver and spleen were impalpable, and upon auscultation only normal hydroaerial noises were heard.

Laboratory results were: sodium $(\mathrm{Na})=138 \mathrm{mEq} / \mathrm{l}$, potassium $(\mathrm{K})=$ $4.6 \mathrm{mEq} / 1$, urea $=46 \mathrm{mg} / \mathrm{dl}$, creatinine $=0.9 \mathrm{mg} / \mathrm{dl}$, hemoglobin $(\mathrm{Hg})=10.6$ $\mathrm{g} / \mathrm{dl}$, hematocrit $(\mathrm{Ht})=32.6 \%$, medium corpuscular volume $=70 \mathrm{~mm} 3$, leukocytes $=8,800,4 \%$ of which being rods, $73 \%$ segmented cells, and $13 \%$ lymphocytes; total bilirubins were $0.4 \mathrm{mg} / \mathrm{dl}$, with $0.2 \mathrm{mg} / \mathrm{dl}$ direct bilirubin, oxaloacetic transaminase $=$ $12 \mathrm{mg} / \mathrm{dl}$, glutamic-pyruvic transaminase $=25 \mathrm{mg} / \mathrm{dl}$, prothrombine activity $75 \%$ FROM normal, and INR (International Normalized Ratio) $=$ 1.2, ATPT (Activated Thromboplastin Time $)=21.1$ seconds $($ Ratio $=0.88)$, thrombin time $=12.3$ seconds (Ratio $=0.87$ ), total serum proteins $=7 \mathrm{~g} / \mathrm{dl}$, with $4 \mathrm{~g} / \mathrm{dl}$ albumin, carcinoembrionic antigen $>10,000 \mathrm{hg} / \mathrm{ml}$ and CA $19.9>222 \mathrm{U} / \mathrm{ml}$.
The patient received nutritional replacement by naso-enteral tube, positioned with the help of per oral endoscopy, thus recovering $1,200 \mathrm{~g}$. The contrasted radiological exam of the esophagus, stomach, and duodenum showed an esophagus of usual topography and normal size, contours, and emptying. The esophagogastric transition was without change. The antro-pyloric region displayed a large filling failure that prevented normal gastric emptying. The diagnosis was: "Proliferative and infiltrative neoplasia of the stomach".

The per-oral endoscopic exam revealed mild erosive esophagitis and hiatal hernia with a $3-\mathrm{cm}$ slide, and an ulcerated lesion in the pre-pyloric region of the stomach. The lesion had infiltrative borders, was vegetating and friable, and easily bled at a touch of the device. The lesion spread through the great curvature, and through the anterior and posterior wall of the pre-pyloric antrum, not allowing the passage of the device. Diagnosis: "Borrmann III-type gastric ulcer lesion, stenosis-inducing, located in the gastric antrum". The biopsy obtained in the endoscopic exam showed little differentiated tubular gastric antrum adenocarcinoma.

The radiographic thorax exam result was normal. The abdomen's ultrasonographic exam showed normal liver, gallbladder, biliary tract, pancreas, and spleen.

The preoperative clinical evaluation showed the patient fitting the classification of the ASA I risk of the American Society of Anesthesiologists.

During the surgery, the presence of para-aortic lymph nodes metastases and peritoneal implantations in the small omentum and liver were confirmed by the pathological exam of frozen sections. Thus the treatment was considered palliative. The patient underwent a subtotal gastrectomy with Billroth II-type, pre-cholic, anisoperistaltic, two-plane reconstruction.

At the end of the procedure, when the last plane of the gastrojejunal anastomosis was being done, the end of the surgery was accelerated because of several cardiovascular changes, while adhering to the best technical norms, with a review of the cavity before closing, which was made through continuous suture in aponeurosis in simple skin stitches.

The surgery took approximately 3 hours and 40 minutes, and anesthesia 5 hours and 10 minutes, with infusion of 4000-ml crystalloids, 40-ml albu$\min$ at $20 \%$, and 3 units erythrocyte concentrate. The laboratory exams requested during surgery and before the incident showed: $\mathrm{Hg}=7.8 \mathrm{~g} / \mathrm{dl}, \mathrm{Ht}$ $=26 \%, \mathrm{Na}=131 \mathrm{mEq} / 1$ and $\mathrm{K}=4.8$ $\mathrm{mEq} / \mathrm{l}$. Despite the ASA I pre-operative evaluation, the patient progressed poorly.

The first alteration-intense bradycardia (cardiac rate $<15 \mathrm{bpm}$ ) that responded well to atropineoccurred during the infusion of the second unit of globule concentrate, following an apparently stable and normal clinical status. After a few minutes, his cardiac rate dropped again (15 to $20 \mathrm{bpm}$ ), with marked hypotension, a drop in $\mathrm{O}_{2}$ saturation to $80 \%$, hepatic congestion, and ischemia of the intestinal loops verified in the operating field, followed by cardiac arrest. Resuscitation was begun with external cardiac massage and administration of adrenaline, resulting in ventricular fibrillation which reverted with electrocardioversion, allowing completion of the surgery. However, while still on the operating table, the patient once again presented bradycardia, hypotension and ventricular fibrillation, and was again cardioverted with success. At this moment, changes in the waveform on the cardiac monitor showed upper unlevelling of the ST segment. The patient developed a new intense 
bradycardia that did not respond to the infusion of dopamine and sodium bicarbonate, nor was there either an oximetric or cardiovascular response following external massage and cardioversion. After 1 hour and a half of resuscitation, and after an additional cardioversion, it was admitted that the condition was irreversible, and the patient was pronounced dead.

The pathological exam of the surgical material showed a 5.1-cm long Borrmann III ulceroinfiltrative neoplasm, located in the great curvature of the gastric antrum, of A moderately differentiated tubular adenocarcinoma histological type, infiltrating even fat from the great curvature; the resection margins were free from neoplastic compromise; vascular and lymphatic invasion was present, perineural invasion was not detected; there was presence of lymph node metastases (10 in 12 lymph nodes researched); presence of metastasis for the designated material as serosa of the hepatic hilus; moderate chronic gastritis in pyloric mucous with complete intestinal metaplasia.

The necropsy performed to check the cause of death revealed the presence of massive, bilateral pulmonary thromboembolism and metastases in pulmonary hilus, mesenteric and peripancreatic lymph nodes.

The final staging was T3, N2, M1, that is: penetration in the gastric wall: $\mathrm{T} 3$, regional lymph node situation: N2 and presence of distant metastasis: M1, which configured stage IV by the UICC TNM classification.

\section{DISCUSSION}

The described case presents some particularities that should be stressed. Usually, thromboembolic phenomena related to surgery occur after the third day following the operation when the patient starts to walk, and up to 30 days after the procedure ${ }^{6}$. In this case, it should be emphasized that the pulmonary embolism took place during surgery. It is evident that the patient had already had thrombosis. That this situation has rarely been reported is noteworthy.

Our experience emphasizes that risk factors for deep venous thrombosis should always be researched prior to surgery. According to Hirsh's ${ }^{7}$ and the European Consensus Group of Thromboembolic Risk Factors' ${ }^{8}$ classification, they are:

- age (40 years or older),

- varices in the lower limbs,

- previous deep venous thrombosis (DVT) or PTE,

- major surgery,

- NEOPLASIA,

- obesity (BMI > 30),

- previous myocardial acute infarction,

- congestive cardiac failure,

- use of estrogen over the last 6 weeks, and

- serious infectious status (localized or sepses).

According to the above classification, a patient at low risk is one presenting 1 risk factor; at moderate risk when presenting 2 to 5 factors, and at high risk when presenting more than 5 factors.

This patient was considered at moderate risk for DVT, as he presented 3 factors: age, major surgery, and neoplasia. In this case, the malignant disease was probably a factor of special relevance to the fatal DVT.

By itself, the neoplasia may interfere with the homeostatic balance. The possible contributing causes towards development of thrombosis in the cancer include the capacity of the tumor cells and their products to interact with the platelets and the fibrinolytic system, as well as with the endothelial and macrophage cells. The release of cytokines, the acute phase reactions, and neovascularization may contribute to activation of the coagulation cascade. Finally, a direct effect of coagulation activation has been proposed, based on pharmacological studies in genetically modified rats with tumor cells 9. GASTRIC adenocarcinoma by itself can promote embolization of the tumor nests in the pulmonary vasculature and result in death, as described by Cheung et al . ${ }^{10}$, but this was not what was found in the necropsy in the present case.

Nevertheless, the high incidence of DVT in some patients may occur due to the association with other factors such as old age, different types of surgery, operative position, and patients bedridden for long periods ${ }^{11}$

Studies show that $25 \%$ of people over 40 years old undergoing general medium-size surgeries lasting more than 45 minutes, without the use of prophylactics develop DVT 12, 13, 14.

In colon-rectal surgery, for instance, it has been observed that the incidence of fatal pulmonary embolism is $3 \%$, with rectal surgeries having greater incidence of thromboembolic phenomena 15,16 .

Although considered AT moderate risk, the fact is that this patient was probably already a bearer of deep venous thrombosis in the preoperative period which, under surgical and anesthetic stress, massively migrated to the pulmonary veins, causing his death. One should ponder whether we should routinely apply other diagnostic methods, such as Doppler'S, even in patients at moderate risk and in case of having a thrombosis diagnosis, to install, prior to the gastrectomy, such devices as filters on the lower Cava vein, thus preventing the migration of thrombi to the pulmonary arteries.

Nowadays, there is a wide variety of prophylactic methods, both mechanical and medicinal, but the prophylaxis issue, when and how to adopt it, as well as the definition of risk groups for DVT, are considerably varied among the different centers. 
The mechanical prophylactic methods involve early walking, passive plantar-dorsal flexion of the feet, elastic compression stockings, electric stimulation of the calves and intermittent pneumatic compression (IPC). In our service, we usually use elastic stockings and encourage early walking and passive exercises. The electric stimulation of the calves is seldom used in our service, and it is indicated only to comatose or anesthetized patients. IPC is a good method, but it is not available in most of our hospitals.

The medicinal options for prophylaxis are: vitamin $\mathrm{K}$ antagonists (oral anticoagulants, which are used primarily in the post-operative period of orthopedic surgeries), heparin in low doses, low molecular weight heparins (LMWH) dextran, dihydroergotamine, and acetylsalicylic acid. The latter three are used less often: dextran, due to the risk of anaphylactic reactions (17), dihydroergotamine because it has been related, in some studies, to the occurrence of arterial failures and myocardial infarction (18), and acetylsalicylic acid because it has not shown to be efficient by itself (19).

However, the use of LMWH IN DVT prophylaxis was only approved for use in the United States in 1986, following the NIH (National Institute of Health) Consensus Conference ${ }^{1}$.

It is known that the association of prophylactic methods, especially LMWH, with the use of elastic compression stockings, additionally reduces the incidence of DVT ${ }^{20}$.

Comparisons between LMWH and heparin in low doses have shown a similar efficiency in preventing DVT, but the LMWHs have some advantages: the administration (once a day) is better accepted by the patient, hemorrhagic complications are less frequent and there is no need for laboratory control 21,22,23. Another study shows that the incidence of DVT in general surgery is $7.6 \%$ when nonfractionated heparin is used, and 3.8\% with the use of LMWH ${ }^{24}$.

Although the current trend is towards the use of LMWHs as medical prophylaxis and, if possible, associating it with some mechanical method ${ }^{25}$, the fact is that in the current case the use of prophylaxis would probably not have prevented the fatal outcome. In contrast to the normal occurrence, thrombosis did not develop following surgery, but was already present in the great veins of the patient, and it migrated at the end of the surgery to the pulmonary arteries, causing death. Only a pre-operative diagnosis and, thus, the consequent installation of an intra-caval filter, could have prevented PTE.

As for diagnosis, Doppler is the image exam of choice for most patients ${ }^{26}$. However, together with venography and scintigraphy by radioisotopes, new methods are being used, such as pulmonary angiography by Magnetic Nuclear Resonance, which is a noninvasive procedure with a sensitivity FROM $75 \%$ to $100 \%$ AND specificity FROM 42\% to $90 \%{ }^{27}$.

It is interesting to note that little attention has been given to the deep venous thrombosis of the upper limbs. Possibly many of these thromboses will go unnoticed since symptoms are much more modest, compared to what happens in thromboses of the lower limb veins. However, the severity of embolism when the thromboses originate in the veins of the upper limb is similar to that observed when they originate in the veins of the lower limbs ${ }^{38}$.

The case reported here shows that one should always research risk factors for DVT, pay attention to the thrombogenic trend of neoplasias, and try to provide the patient with some prophylactic method, since the DVT and PTE incidences are not minor, and their consequences are very serious.
BRESCIANI, C. e col. - Tromboembolismo pulmonar fatal no intraoperatório de gastrectomia por adenocarcinoma gástrico: relato de caso. Rev. Hosp. Clín. Fac. Med. S. Paulo 54(4): 115 - 120,1999.
Relata-se um caso de paciente com adenocarcinoma gástrico com indicação de gastrectomia.

$\mathrm{O}$ ato operatório transcorreu sem anormalidades. Foi realizada gastrectomia subtotal paliativa, pois encon- trou-se linfonodos para-aórticos comprometidos pela neoplasia, confirmado por exame anátomo-patológico de congelação realizado no decorrer da intervenção. Ao fim da confecção da gastroêntero-anastomose o paciente 
passou a apresentar bradicardia intensa: 38 batimentos por minuto (bpm), hipotensão arterial, alterações do traçado do eletrocardiograma (Supra-desnivelamento do segmento ST) e parada cardíaca.
Realizadas as manobras de ressucitação com sucesso temporário, já que a seguir o paciente apresentou novo colapso circulatório, sendo novamente recuperado, finalmente a $3^{\mathrm{a}}$ parada cardíaca foi irreversível e constatou-se o óbito intra-operatório.

DESCRITORES: Tromboembolismo. Anticoagulação. Profilaxia. Adenocarcinoma gástrico. Gastrectomia.

\section{REFERENCES}

1. NIH Consensus Conference - Prevention of venous thrombosis and pulmonary embolism. JAMA 1986; 256:744-749.

2. GALLUS A S, SALZMAN E W \& HIRSH J-Prevention of venous thromboembolism. In: COLMAN R W, HIRSH J, MARDET V J et al. - Hemostasis and Thrombosis: Basic Principles and Clinical Practice. $3^{\text {th }}$ ed. Philadelphia, Lippincott, 1994. p. 1331-1345.

3. VON STRAUCH M - Über venenthrombose der unteren extremitäten nach köeliotomien bei beckenhochlagerung und äthernarkose. Centralbl Gynäkol 1894; 13:304-306.

4. DAHL-IVERSEN E - Tre aars erfaringer over postoperativ phlebitis, thrombose og emboli hos patienter oppegaaende fra dagen efter operationen. Nord Med 1945; 28:2085-2088.

5. INTERNATIONAL MULTICENTER TRIAL - Prevention of fatal postoperative pulmonary embolism by low doses of heparin. Lancet $1975 ; \mathbf{2}: 45-51$.

6. SCURR J H - How long after surgery does the risk of thromboembolism persist? Acta Chir Scand 1990; 556:22-24.

7. HIRSH J-Comparison of general and regional anesthesia as a risk factor for deep vein thrombosis following hip surgery. A critical review. Thromb Haemost 1990; 64:497-500.

8. THROMBOEMBOLIC RISK FACTORS (THRIFT) CONSENSUS GROUP - Risk of and prophylaxis for venous thromboembolism in hospital patients. BMJ 1992; 305:567-574.

9. DONATI M B - Cancer and thrombosis. Haemostasis 1994; 24:128131.

10. CHEUNG T C et al. - Occult gastric cancer presenting as cor pulmonale resulting from tumor cell microembolism. Am J Gastroenterol 1997; 92:1057-1059.

11. KJAERGAARD J, ESBENSEN K, WILLE-JORGENSEN P et al - A multivariate pattern recognition study of risk-factors indicating postoperative thromboembolism despite low dose heparin in major abdominal surgery. Thromb Haemost 1985; 341:409-412.

12. MAFFEI F H A et al - Incidência de trombose venosa profunda dos membros inferiores em doentes submetidos à cirurgia abdominal. Rev Ass Med Bras 1987; 33:103-108.

13. SAMAMA M M - Prevention of postoperative thromboembolism in general surgery with enoxaparin. Eur J Surg Acta Chir (Suppl.) 1994; 571:31-33.

14. FORBES C D - Prevention of deep vein thrombosis - use of the low molecular weight heparin enoxaparin. Br J Clin Proct 1989; 43:396-400.

15. TÖRNGREN S - Pulmonary embolism and postoperative death. Acta Chir Scand 1983; 149:269-271.

16. WILLE-JORGENSEN P, KJAERGAARD J, JORGENSES T et al. - Failure of prophylatic management of thromboembolic disease o f colorectal surgery. Dis Colon Rectum 1988; 31:384-386.

17. LJUNGSTRÖN K G - The antithrombotic efficacy of dextran. Acta Chir Scand 1988; 543:26-30.

18. COMEROTA A J \& WHITE J W - The use of dihydroergotamine and heparin in the prophylaxis of deep venous thrombosis. Chest 1986; 89:389-395.

19. CLAGETT G P \& REISCH J S - Prevention of venous thromboembolism general surgical patients. Ann Surg 1988; 208:227240.

20. EUROPEAN FRAXIPARIN STUDY GROUP - Comparison of low molecular weight heparin and unfractionated heparin for the prevention of deep vein thrombosis in patients undergoing abdominal surgery. Br J Surg 1988; 75: 1058-1063.

21. BERGQVIST D, LOWE G D O \& BERSTAD A - Low molecular weight heparin once daily compared with conventional low-dose heparin twice daily. A prospective double-blind multicentre trial on prevention of postoperative thrombosis. Br J Surg 1986; 73:204-208.

22. KAKKAR V V, COHEN A T, EDMONSON R A et al. - Low molecular weight versus standard heparin for prevention of venous thromboembolism after major abdominal surgery. Lancet 1993; 341:259-265.

23. MANSO L C, MILHEIRO A \& CASTRO E SOUSA F Prophylaxis of postoperative thromboembolism. Randomized prospective study. - Acta Med Port 1996; 9: 87-90. 
24. SAMAMA M M, BERNARD P, BONNARDOT J P et al. - Low molecular weight heparin compared with unfractionated heparin in prevention of postoperative thrombosis. Br J Surg 1988; 75:128-131.25.

25. HAAS S - Antithromboembolic efficacy and safety of enoxaparin in general surgery. German multicentric trial. Eur J Surg Acta Chir (Suppl) 1994; 571:37-43.

26. Barloon T J, Bergus G R \& Seabold J E - Diagnostic imaging of lower limb deep venous thrombosis. Am Fam Physician 1997;56: 791-801.
27. ERDMAN W A \& CLARKE G D - Magnetic resonance imaging of pulmonary embolism. Sem in Ultrasound CT MR 1997;18: 338348.

28. HINGORANI A, ASCHER E, LORENSON E et al. - Upper extremity deep venous thrombosis and its impact on morbidity and mortality rates in a hospital-based population. J Vasc Surg 1997; 26:853-860.

Received for publication on the 10/05/99 